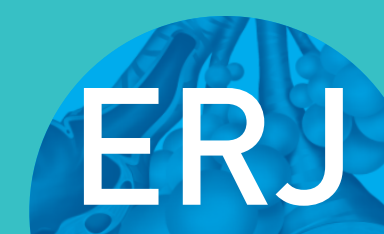

open research
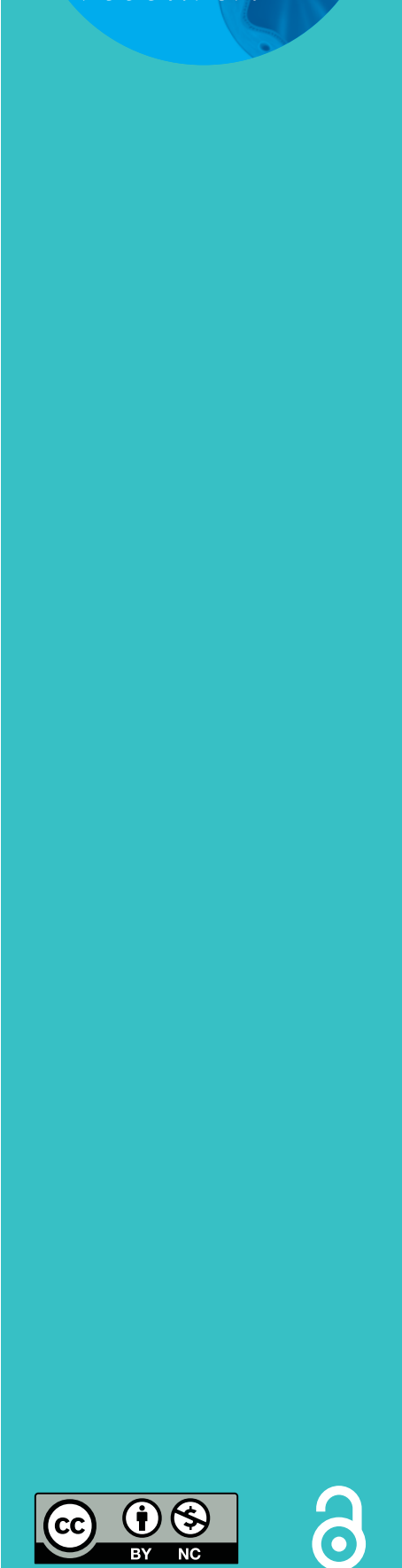

\section{Sleep disordered breathing and autonomic function in overweight and obese children and adolescents}

\author{
Annelies Van Eyck ${ }^{1,2}$, Kim Van Hoorenbeeck ${ }^{1,2}$, Benedicte Y. De Winter ${ }^{1}$, \\ Luc Van Gaal ${ }^{1,3}$, Wilfried De Backer ${ }^{1,4}$ and Stijn L. Verhulst ${ }^{1,2}$
}

Affiliations: ${ }^{1}$ Laboratory of Experimental Medicine and Pediatrics, University of Antwerp, Antwerp, Belgium. ${ }^{2}$ Dept of Paediatrics, Antwerp University Hospital, Edegem, Belgium. ${ }^{3}$ Dept of Endocrinology, Diabetology and Metabolism, Antwerp University Hospital, Edegem, Belgium. ${ }^{4}$ Dept of Pulmonology, Antwerp University Hospital, Edegem, Belgium.

Correspondence: Annelies Van Eyck, Laboratory of Experimental Medicine and Pediatrics, University of Antwerp, Universiteitsplein 1, 2610 Antwerp, Belgium. E-mail: Annelies.vaneyck@uantwerpen.be

ABSTRACT Obstructive sleep apnoea (OSA), common in children with obesity, is associated with cardiovascular morbidity. Autonomic dysfunction has been suggested to be a key player in the development of these complications. We investigated the relationship between obesity, OSA and sympathetic activity in children.

191 children with obesity were included and distributed into two groups: 131 controls and 60 with OSA. Beat-to-beat RR interval data were extracted from polysomnography for heart rate variability analysis. Urinary free cortisol levels were determined.

Urinary free cortisol did not differ between groups and was not associated with OSA, independent of the level of obesity. Differences in heart rate variability measures were found: mean RR interval decreased with OSA, while low/high-frequency band ratio and mean heart rate increased with OSA. Heart rate variability measures correlated with OSA, independent of obesity parameters and age: oxygen desaturation index correlated with mean heart rate $(\mathrm{r}=0.19, \mathrm{p}=0.009)$ and mean $\mathrm{RR}$ interval $(\mathrm{r}=-0.18, \mathrm{p}=0.02)$, while high-frequency bands and low/high-frequency band ratio correlated with arterial oxygen saturation measured by pulse oximetry $\left(\mathrm{SpO}_{2}\right)(\mathrm{r}=-0.20, \mathrm{p}=0.008$ and $\mathrm{r}=-0.16, \mathrm{p}=0.04)$ and $\mathrm{SpO}_{2}$ nadir $(\mathrm{r}=0.23$, $\mathrm{p}=0.003$ and $\mathrm{r}=-0.19, \mathrm{p}=0.02)$.

These results suggest that sympathetic heart activity is increased in children with obesity and OSA. Measures of hypoxia were related to increased sympathetic tone, suggesting that intermittent hypoxia is involved in autonomic dysfunction.

@ERSpublications

Sympathetic heart activity is increased in children with obstructive sleep apnoea and obesity http://ow.ly/iSVc305AZRv

Received: March 172016 | Accepted after revision: Oct 152016

Conflict of interest: Disclosures can be found alongside this article at openres.ersjournals.com

Copyright $\odot$ ERS 2016. This article is open access and distributed under the terms of the Creative Commons Attribution Non-Commercial Licence 4.0. 


\section{Introduction}

Sleep disordered breathing (SDB) is a well-known complication of obesity in adults and children. It includes primary snoring, upper airway resistance syndrome and obstructive sleep apnoea (OSA). OSA is the most severe entity in the spectrum of SDB, and is characterised by intermittent cycles of upper airway collapse associated with hypoxia and arousal during sleep. It is a prevalent disorder in childhood, affecting 2-3\% of children [1]. However, the prevalence of OSA has been reported to be as high as $59 \%$ in the context of childhood obesity [2]. The difference in prevalence may be related to a different underlying phenotype distinguishing OSA in obese children from that in normal-weight children [3]. Several complications are associated with OSA in childhood, including cardiovascular, neurological and metabolic complications [4-6]. However, the linking mechanisms between OSA and its associated complications remain unclear. Previous studies in an obese paediatric population did not find any relationship between OSA, systemic inflammation or adipokine secretion [7,8], in contrast to a normal-weight paediatric population [9-11]. Therefore, other options need to be explored. Autonomic dysfunction has been suggested as a key feature in the development of cardiac and metabolic consequences of both adult and paediatric OSA $[4,12,13]$. It is expected that the sympathetic tone increases while the parasympathetic tone decreases in patients with OSA. Heart rate variability (HRV) describes the variation between consecutive heart beats, and the regulation of HRV stems from the parasympathetic and sympathetic nervous systems [14]. Consequently, HRV can be used as a quantitative marker for autonomic nervous system function. Previous studies have investigated the relationship between HRV and OSA in children [15-17]. However, none of these studies focused on a paediatric overweight and obese population as they only included normal-weight subjects.

Furthermore, arousals are associated with hypothalamic-pituitary-adrenal (HPA) axis activation and associated sympathetic activation [18]. Cortisol is the primary human glucocorticoid product of the HPA axis and it is thereby expected that cortisol levels would be higher in patients with OSA. Literature linking HPA function and OSA in adults has been conflicting [19], and data from children is scarce.

Our goal was to investigate the relationship between OSA and sympathetic activity in overweight and obese children by examining HRV and cortisol levels. The following hypotheses were examined: 1) OSA is associated with an increase in sympathetic heart activity as measured by HRV and 2) cortisol levels are increased in patients with OSA.

\section{Materials and methods}

Study population

In this prospective study, consecutive overweight and obese children were recruited between June 2010 and May 2015 at the Paediatric Obesity Clinic of Antwerp University Hospital (Antwerp, Belgium). Children were excluded in case of infection, a chronic medical condition, or genetic, neuromuscular or craniofacial syndromes. The Ethics Committee of Antwerp University Hospital approved this study, and informed consent was obtained from the patients and their parents or legal guardians.

\section{Anthropometry}

All measurements were performed in the morning, after an overnight fast with patients undressed. Height, weight, waist circumference and waist-to-hip ratio (WHR) were measured using standardised techniques by skilled personnel. Fat mass was measured with bioelectrical impedance analysis, using the Deurenberg formula for children [20]. Body mass index (BMI) was calculated $\left(\mathrm{kg} \cdot \mathrm{m}^{-2}\right)$ and was further analysed as Z-scores, using the Flemish growth study as a reference population [21]. Overweight and obesity were defined according to the International Obesity Task Force criteria [22].

\section{Cortisol}

24-h urine collection was conducted to determine the urinary free cortisol (UFC) levels. UFC levels were measured using ultra-performance liquid chromatography followed by mass spectrometry (Acquity UPLC-TQD; Waters, Milford, MA, USA). UFC levels between 7 and $52 \mu \mathrm{g} \cdot 24 \mathrm{~h}^{-1}$ were considered normal.

\section{Polysomnography}

All children underwent nocturnal polysomnography for at least $6 \mathrm{~h}$. The following variables were continuously measured and recorded by a computerised polysomnograph (Brain RT; OSG, Rumst, Belgium): electroencephalography (C4/Al and C3/A2), electro-oculography, electromyography of anterior tibial and chin muscles, and electrocardiography. Respiratory effort was measured by respiratory inductance plethysmography and arterial oxygen saturation $\left(\mathrm{S}_{2} \mathrm{O}_{2}\right)$ was measured by a finger probe connected to a pulse oximeter. Airflow was measured by means of a nasal pressure cannula and thermistor, and snoring was detected by means of a microphone at the suprasternal notch. All patients were monitored on audio/videotape using an infrared camera. Respiratory events were scored according to the American Academy of Sleep Medicine guidelines [23]. 
The obstructive apnoea-hypopnoea index (oAHI) was defined as the average number of obstructive apnoea and hypopnoea events per hour of sleep. Mild OSA was diagnosed by the presence of an oAHI between 2 and 5 events. $\mathrm{h}^{-1}$ and moderate-to-severe OSA was defined by an oAHI $\geqslant 5$ events. $\mathrm{h}^{-1}$ [24]. The respiratory disturbance index (RDI) was calculated as the sum of the recorded apnoeas and hypopnoeas divided by the total sleep time (TST). All desaturations of $\geqslant 3 \%$ from the baseline oxygen saturation were quantified and the oxygen desaturation index (ODI) was calculated as the total of desaturations divided by the TST.

\section{Heart rate variability analysis}

Beat-to-beat RR interval data were extracted from polysomnogram measurements and imported into Kubios HRV analysis software (Dept of Applied Physics, University of Eastern Finland, Kuopio, Finland) [25]. HRV was assessed in the time and frequency domains.

Time domain assessment is applied straight to the series of successive RR intervals and yields the following parameters: mean RR interval, mean heart rate (HR) and standard deviation of RR intervals (normal sinusto-normal sinus interbeat intervals $(\mathrm{SDNN})$ ). Of these variables, only SDNN gives information on the variability and an increase in SDNN suggests an increase in HRV.

For the frequency domain, a fast Fourier transform spectral analysis was used. This results in specific frequency bands, which correspond with specific physiological mechanisms. High-frequency (HF) bands are a reflection of the parasympathetic activity, while low-frequency (LF) bands are a reflection of both parasympathetic and sympathetic activity. As a result, LF/HF band ratio is a marker for sympathetic activity.

\section{Statistical analysis}

Statistical analysis was performed using SPSS version 23.0 (SPSS, Chicago, IL, USA). Normality was tested by the Kolmogorov-Smirnov test. Normally distributed data are presented as mean \pm SD. Skewed data are reported as median (range, i.e. minimum-maximum). Patients were distributed in groups based on their oAHI. Groups were compared by means of the Chi-squared test, independent sample t-test or Mann-Whitney U-test. Correlations between measures of sympathetic activity and other variables were calculated using Pearson's or Spearman's correlation analysis as appropriate.

Linear regression analysis was performed in case of a significant correlation between measures of sympathetic activity and sleep parameters to determine if the correlation persisted after controlling for the degree of adiposity. As the different measures of adiposity are highly intercorrelated, linear regression was done by the inclusion of one measure of adiposity with the highest univariate correlation coefficient for the respective outcome (BMI z-score, waist circumference, WHR and fat mass). For all analyses, $\mathrm{p} \leqslant 0.05$ was considered statistically significant.

\section{Results}

A total of 191 overweight and obese children were included in this study with a mean BMI of 30.3 (range 19.7-47.3) $\mathrm{kg} \cdot \mathrm{m}^{-2}$, which corresponds to a mean z-score of 2.5 (range 1.5-4.1). Mean age was 12 (range $5-18$ ) years and $36 \%$ of subjects were male. OSA was diagnosed in 60 children (31.4\%): 32 children had mild OSA (16.7\%) and 28 children had moderate-to-severe OSA (14.7\%). Characteristics of patients with and without sleep apnoea are compared in table 1 . No significant differences in patient characteristics between the groups were found except for WHR, which was significantly higher in the OSA group. Sleep-related respiratory parameters were significantly different between groups, as expected.

In our population, 51 patients had elevated UFC (33 controls and 18 OSA). However, UFC did not differ between patients with and without OSA. Mean $\mathrm{SpO}_{2}$ correlated with UFC ( $\left.\mathrm{r}=-0.21, \mathrm{p}=0.01\right)$, but this relationship did not persist after correction for waist circumference $(\mathrm{p}=0.3)$. The percentage of TST with $\mathrm{S}_{2}$ $>95 \%$ (TST95) also correlated with UFC $(r=0.24, p=0.005)$, but again this relationship did not persist after correction for waist circumference $(\mathrm{p}=0.9)$. UFC $(\mathrm{r}=0.33, \mathrm{p}<0.001)$ was also positively correlated with age.

Mean RR interval was significantly lower in patients with OSA, while LF/HF ratio and mean HR were significantly higher in patients with OSA. Measures for sympathetic activity are compared between groups in table 2. Several correlations were found between various sleep-related respiratory parameters and measures of HRV (table 3). In particular, LF/HF band ratio correlated with almost all measures of SDB (oAHI, RDI, mean $\mathrm{S}_{\mathrm{PO}_{2}}, \mathrm{~S}_{\mathrm{PO}_{2}}$ nadir and TST95). Correlations between measures of adiposity and measures of $\mathrm{HRV}$, as well as between age and measures of HRV, are shown in table 4. BMI z-score and WHR did not correlate with any measures of HRV. Mean RR and LF/HF band ratio were positively correlated with the waist circumference, while mean HR and HF bands were negatively correlated with the waist circumference. Age was positively associated with mean RR, SDNN and LF/HF band ratio, while mean HR was negatively associated with age.

Linear regression analysis was performed when measures of HRV correlated with both sleep-related respiratory parameters and measures of adiposity. Only mean HR remained significantly correlated with 


\begin{tabular}{|c|c|c|c|}
\hline & Non-OSA & OSA & p-value \\
\hline Subjects & 131 & 60 & \\
\hline Male/female & 44/87 & $24 / 36$ & $0.4^{\#}$ \\
\hline Age years & $12(6-18)$ & $11(5-17)$ & $0.1^{\Uparrow}$ \\
\hline Height m & $1.55(1.14-1.83)$ & $1.51(1.07-1.86)$ & $0.1^{\pi}$ \\
\hline Weight kg & $71.0(30.4-129.8)$ & $67.3(28.0-137.0)$ & $0.3^{\pi}$ \\
\hline BMI z-score & $2.5(1.5-3.5)$ & $2.5(1.7-4.1)$ & $0.6^{\pi}$ \\
\hline Waist circumference $\mathrm{cm}$ & $92.4 \pm 13.6$ & $93.2 \pm 17.1$ & $0.7^{+}$ \\
\hline WHR & $0.89(0.75-1.02)$ & $0.92(0.79-1.04)$ & $<0.001^{\uparrow}$ \\
\hline Fat mass $\%$ & $36.9(25.7-60.4)$ & $36.1(27.3-53.1)$ & $0.9^{9}$ \\
\hline TST min & $512(169-637)$ & $512(293-648)$ & $0.6^{\pi}$ \\
\hline oAHI events $\cdot h^{-1}$ & $0.5(0.0-1.9)$ & $4.9(2.0-67.3)$ & $<0.001^{\uparrow}$ \\
\hline RDI events $\cdot h^{-1}$ & $0.85(0.00-4.80)$ & $5.90(2.00-67.70)$ & $<0.001^{\uparrow}$ \\
\hline Mean $\mathrm{SpO}_{2} \%$ & $97.2(91.2-98.2)$ & $96.7(91.9-98.6)$ & $0.001^{\uparrow}$ \\
\hline $\mathrm{SpO}_{2}$ nadir \% & $93(80-100)$ & $91(81-100)$ & $<0.001^{\pi}$ \\
\hline TST95 \% & $99.7(25.6-100.0)$ & $98.0(2.4-100.0)$ & $<0.001^{\uparrow}$ \\
\hline ODI events $\cdot \mathrm{h}^{-1}$ & $0.3(0.0-8.4)$ & $0.8(0.0-33.8)$ & $<0.001^{\uparrow}$ \\
\hline N1 \%TST & $2(0-13)$ & $2(0-16)$ & 0.6 \\
\hline N2 \%TST & $51(28-72)$ & $45(8-65)$ & $<0.001$ \\
\hline N3 \%TST & $22(4-48)$ & $28(8-65)$ & $<0.001$ \\
\hline REM \%TST & $23(0-36)$ & $23(5-37)$ & 0.7 \\
\hline \multicolumn{4}{|c|}{$\begin{array}{l}\text { Data are presented as } \mathrm{n} \text {, mean } \pm \mathrm{SD} \text { or median (range), unless otherwise stated. } \mathrm{BMI} \text { : body mass index; } \\
\text { WHR: waist-to-hip ratio; } \mathrm{TST} \text { : total sleep time; oAHI: obstructive apnoea-hypopnoea index; RDI: respiratory } \\
\text { disturbance index; } \mathrm{SpO}_{2} \text { : arterial oxygen saturation measured by pulse oximetry; TST95: TST with } \mathrm{SpO}_{2} \\
>95 \% \text {; ODI: oxygen desaturation index; N1-N3: sleep stages; REM; rapid eye movement. \#: Chi-squared } \\
\text { test; }^{n} \text { : Mann-Whitney U-test; }{ }^{+} \text {: independent sample t-test. } \mathrm{p} \leqslant 0.05 \text { was considered statistically significant. }\end{array}$} \\
\hline
\end{tabular}

$\mathrm{oAHI}$ after correction for waist circumference $(\mathrm{r}=0.158, \mathrm{p}=0.03)$. RDI remained correlated with both mean $\mathrm{RR}$ interval $(\mathrm{r}=-0.15, \mathrm{p}=0.04)$ and mean $\mathrm{HR}(\mathrm{r}=-0.33, \mathrm{p}=0.02)$ after correction for waist circumference. $\mathrm{HF}$ bands and LF/HF band ratio remained significantly correlated with mean $\mathrm{SpO}_{2}(\mathrm{r}=-0.20, \mathrm{p}=0.008$ and $\mathrm{r}=-0.16, \mathrm{p}=0.04)$ and $\mathrm{SpO}_{2}$ nadir $(\mathrm{r}=0.23, \mathrm{p}=0.003$ and $\mathrm{r}=-0.19, \mathrm{p}=0.02)$ after correction for waist circumference. $\mathrm{SpO}_{2}$ nadir also remained correlated with mean $\mathrm{RR}$ interval $(\mathrm{r}=0.15, \mathrm{p}=0.04)$. ODI was still correlated with mean $R R$ interval $(r=-0.18, p=0.02)$ and mean $H R(r=0.19, p=0.009)$ after correction for waist circumference. A final model for the mean HR, mean RR interval, HF bands and LF/HF band ratio is given in table 5 .

\section{Discussion}

Sympathetic activity is increased in overweight and obese children with sleep apnoea. Measures of hypoxia, in particular, were related to frequency domain measures for HRV, indicating a lower parasympathetic and

TABLE 2 Urinary free cortisol (UFC) levels and heart rate variability parameters of subjects with and without obstructive sleep apnoea

\begin{tabular}{|c|c|c|c|}
\hline & OAHI $<2$ & $\mathrm{OAHI} \geqslant 2$ & p-value \\
\hline UFC $\mu g \cdot 24 h^{-1}$ & $36(1-157)$ & $46(12-171)$ & $0.7^{\Uparrow}$ \\
\hline Mean RR interval ms & $802.3(598.3-1182.4)$ & 758.7 (605.2-1006.3) & $0.02^{\text {Il }}$ \\
\hline SDNN ms & $96.9(34.6-198.7)$ & $94.5(39.6-177.2)$ & $0.3^{9}$ \\
\hline Mean HR beats $\cdot \min ^{-1}$ & $75.88 \pm 9.79$ & $80.20 \pm 9.66$ & $0.008^{\#}$ \\
\hline LF bands $\%$ & $15.5(5.4-30.5)$ & $17.0(8.3-40.4)$ & $0.07^{\pi}$ \\
\hline HF bands $\%$ & $21.4(3.2-63.2)$ & $20.2(2.3-54.4)$ & $0.4^{9}$ \\
\hline LF/HF band ratio & $0.707(0.168-2.963)$ & $0.962(0.242-12.215)$ & $0.05^{\pi}$ \\
\hline \multicolumn{4}{|c|}{$\begin{array}{l}\text { Data are presented as median (range) or mean } \pm \text { SD, unless otherwise stated. oAHI: obstructive apnoea- } \\
\text { hypopnoea index; UFC: urinary free cortisol; SDNN: standard deviation of RR intervals (normal sinus-to- } \\
\text { normal sinus interbeat intervals); HR: heart rate; LF: low-frequency; HF: high-frequency. }{ }^{\text {\# }} \text { : independent } \\
\text { sample t-test; }{ }^{\uparrow}: \text { Mann-Whitney U-test. } p \leqslant 0.05 \text { was considered statistically significant. }\end{array}$} \\
\hline
\end{tabular}




\begin{tabular}{|c|c|c|c|c|c|c|}
\hline & OAHI & RDI & Mean $\mathrm{SpO}_{2}$ & $\mathrm{SpO}_{2}$ nadir & TST95 & ODI \\
\hline $\begin{array}{l}\text { Mean RR interval } \\
\text { SDNN }\end{array}$ & $-0.15^{\#}$ & $-0.18^{\#}$ & & $0.15^{\#}$ & & $-0.23^{\natural}$ \\
\hline $\begin{array}{l}\text { Mean HR } \\
\text { LF bands }\end{array}$ & $0.16^{\#}$ & $0.19^{\#}$ & & & & $0.23^{\text {I }}$ \\
\hline $\begin{array}{l}\text { HF bands } \\
\text { LF/HF band ratio }\end{array}$ & $0.17^{\#}$ & $0.17^{\#}$ & $\begin{array}{r}0.22^{9} \\
-0.23^{9}\end{array}$ & $\begin{array}{r}0.18^{\#} \\
-0.20^{9}\end{array}$ & $\begin{array}{r}0.25^{\text {ๆ }} \\
-0.25^{\text {ๆ }}\end{array}$ & \\
\hline
\end{tabular}

Only significant Spearman correlation coefficients are shown. oAHI: obstructive apnoea-hypopnoea index; $\mathrm{RDI}$ : respiratory disturbance index; $\mathrm{SpO}_{2}$ : arterial oxygen saturation measured by pulse oximetry; TST95: percentage of total sleep time with $\mathrm{SpO}_{2}>95 \%$; ODI: oxygen desaturation index; SDNN: standard deviation of RR intervals (normal sinus-to-normal sinus interbeat intervals); HR: heart rate; LF: low-frequency; HF: high-frequency. ${ }^{\#}: p \leqslant 0.05 ;{ }^{\uparrow}: p \leqslant 0.01$.

a higher sympathetic activity. Mean $\mathrm{HR}$ and mean RR interval were also correlated with the ODI, suggesting a role for OSA in the regulation of the autonomic nervous system. No relationship between UFC levels and sleep-related respiratory measures was found in our population.

HR is under autonomic control, with the parasympathetic nerves being responsible for a decrease in HR and the sympathetic nerves being responsible for an increase in HR. In our population HR was significantly higher in patients with OSA, which implies an elevated sympathetic activity. In addition, mean RR interval decreased in the presence of sleep apnoea. Adenotonsillectomy, which is the first-line treatment for OSA in normal-weight children, has been shown to increase mean RR interval in children [26, 27], again suggesting that autonomic nerve function is influenced by SDB. A lower mean RR interval indicates a higher HR, which in turn is an indication for increased sympathetic activity. However, mean HR and mean RR interval do not give any information on HRV. In contrast, SDNN will increase when there is an increase in HRV. We could not find any effect of OSA on SDNN in our population of overweight and obese children. This is in contrast to a study by LIAO et al. [15], who found a lower SDNN in paediatric patients with SDB. The HF band is a reflection of parasympathetic activity, while the LF band is a reflection of both parasympathetic and sympathetic activity. Consequently, LF/HF band ratio is a ratio of parasympathetic to sympathetic activity and an elevation of this ratio is a sign of higher sympathetic activity. Indeed, in our population LF/HF band ratio was significantly higher in patients with sleep apnoea. Furthermore, a high LF/HF band ratio was related to a lower mean $\mathrm{SpO}_{2}$ and a lower $\mathrm{SpO}_{2}$ nadir. We hypothesise that hypoxia associated with OSA could lead to autonomic imbalance, favouring sympathetic activity. This was further confirmed by the positive correlation between HF bands and measures of hypoxia. It is likely that intermittent hypoxia mediates the elevation in sympathetic nerve activity. Previous studies in normal-weight children have also found indications for an increased sympathetic activity with OSA [15, 28].

The study of the autonomic dysfunction is also of clinical interest in the context of obesity. Autonomic nervous system dysfunction may contribute to the development or stabilisation of obesity. Previous studies that investigated the autonomic nervous system in obese children found a decrease in parasympathetic activity and increased sympathetic tone [29-31]. Therefore, obesity needs to be considered as a confounding

TABLE 4 Spearman correlation analysis between measures of adiposity and age and measures of heart rate variability

\begin{tabular}{|c|c|c|c|}
\hline & Waist & Fat mass & Age \\
\hline Mean RR interval & $0.34^{+}$ & \multirow{6}{*}{$-0.20^{\#}$} & $0.46^{+}$ \\
\hline SDNN & & & $0.20^{\text {? }}$ \\
\hline Mean HR & $-0.34^{+}$ & & \multirow[t]{2}{*}{$-0.47^{+}$} \\
\hline LF bands & & & \\
\hline HF bands & $-0.24^{9}$ & & \multirow{2}{*}{$0.17^{\#}$} \\
\hline LF/HF band ratio & $0.21^{\Upsilon 1}$ & & \\
\hline $\begin{array}{l}\text { Only significant Spe } \\
\text { SDNN: standard de } \\
\text { LF: low-frequency; }\end{array}$ & $\begin{array}{l}\text { efficient } \\
\text { ls Inorm } \\
: p \leqslant 0.05\end{array}$ & $\begin{array}{l}\text { dy mass in } \\
\text { inus interbe } \\
1 .\end{array}$ & $\begin{array}{l}\text { ip ratio; } \\
\text { art rate; }\end{array}$ \\
\hline
\end{tabular}




\begin{tabular}{|c|c|c|c|}
\hline & $r$ & $r^{2}$ & p-value \\
\hline \multicolumn{4}{|l|}{ Mean HR } \\
\hline oAHI & 0.10 & 0.26 & 0.1 \\
\hline RDI & 0.11 & 0.27 & 0.1 \\
\hline $\mathrm{ODI}^{\#}$ & 0.15 & 0.27 & 0.03 \\
\hline $\mathrm{Age}^{\#}$ & -0.36 & & $<0.001$ \\
\hline Waist & 0.10 & & 0.1 \\
\hline \multicolumn{4}{|l|}{ Mean RR } \\
\hline RDI & -0.88 & 0.25 & 0.2 \\
\hline $\mathrm{SpO}_{2}$ nadir & 0.06 & 0.26 & 0.4 \\
\hline $\mathrm{ODI}^{\#}$ & -0.13 & 0.26 & 0.05 \\
\hline $\mathrm{Age}^{\#}$ & 0.37 & & $<0.001$ \\
\hline Waist & -0.12 & & 0.1 \\
\hline \multicolumn{4}{|l|}{ HF bands } \\
\hline Mean $\mathrm{SpO}_{2}{ }^{\#}$ & 0.20 & 0.11 & 0.007 \\
\hline $\mathrm{SpO}_{2}$ nadir $^{\#}$ & 0.22 & 0.11 & 0.005 \\
\hline Age & 0.08 & & 0.3 \\
\hline Waist $^{\#}$ & -0.19 & & 0.01 \\
\hline \multicolumn{4}{|c|}{ LF/HF band ratio } \\
\hline Mean $\mathrm{SpO}_{2}{ }^{\#}$ & -0.16 & 0.03 & 0.04 \\
\hline $\mathrm{SpO}_{2}$ nadir $^{\#}$ & -0.18 & 0.04 & 0.02 \\
\hline Age & -0.05 & & 0.6 \\
\hline Waist & 0.05 & & 0.5 \\
\hline \multicolumn{4}{|c|}{$\begin{array}{l}\mathrm{HR} \text { : heart rate; } \mathrm{OAHI} \text { : obstructive apnoea-hypopnoea index; } \mathrm{RDI} \text { : respiratory disturbance index; } \mathrm{SpO}_{2} \text { : arterial } \\
\text { oxygen saturation measured by pulse oximetry; ODI: oxygen desaturation index. Due to multicollinearity, the } \\
\text { sleep-related respiratory parameters could not be fitted in a single regression model. Therefore, each } \mathrm{r}^{2} \text {-value } \\
\text { represents a separate regression model with the sleep-related respiratory parameter as an independent } \\
\left.\text { variable, controlling for age and waist circumference. }{ }^{\#} \text { : significant contributors for the model ( } p \leqslant 0.05\right) \text {. }\end{array}$} \\
\hline
\end{tabular}

factor when studying the relationship between OSA and sympathetic activity. Measures of HRV were not correlated with BMI in our population, confirming that this is not the best marker for obesity. However, measures of central obesity (e.g. waist circumference and WHR) were correlated with both HRV and UFC in our population. Moreover, the relationship observed between measures of hypoxia and UFC was solely due to the effect of obesity.

To the best of our knowledge, no other studies have examined the relationship between autonomic function and OSA in an overweight and obese paediatric population. NARKIEWICZ et al. [32] investigated the relationship between OSA, sympathetic activity and obesity in an adult population. In contrast to our results, they found that obesity in the absence of OSA was not accompanied by increased sympathetic activity. However, they did not study cardiac autonomic function via HRV, but measured muscle sympathetic activity using microneurography. It is possible that the sympathetic nervous system, outside of cardiac autonomic nerve function, is not affected by obesity. However, BAUM et al. [31] found an effect on sympathetic activity using pupillography in obese children. Literature about the relationship between OSA and cortisol in adults has been conflicting [19]. It is possible that the positive studies did not account for obesity in their population, which could explain these discrepancies. Chronic stressful events such as OSA could affect cortisol levels differently in paediatric patients compared with adults and therefore results of adult studies should only be cautiously applied to a paediatric population. Studies in children have been scarce, with most studies examining salivary cortisol levels. MALAKASIOTI et al. [33] described a decrease of salivary cortisol levels in children with OSA and hypertrophic tonsils, while PATACCHIoli et al. [34] found increased morning salivary cortisol in patients with OSA. In contrast, we could not find any effect of OSA on UFC levels.

Age is also a confounding factor that needs to be considered when studying the autonomic nervous system, as studies have shown an increase of sympathetic tone with increasing age $[35,36]$. This was also evident from our results, as almost all measures of HRV were correlated with age. In our final model age had the largest effect on both mean HR and mean RR interval, while ODI had only a smaller effect. This effect of age could explain the different result found in adults and children.

The autonomic nervous system is an important regulator in major organs, including the liver, adipose tissue and pancreas, whereby alterations in autonomic function could contribute to metabolic dysfunction 
$[37,38]$. As our results indicate that OSA is strongly connected to autonomic dysfunction, it is likely that these autonomic alterations do not only have an effect on the cardiovascular system, but also contribute to the increased presence of metabolic complications in the context of OSA.

Several study limitations need to be considered. First, HRV analysis was only obtained during the night-time, so these results might not be applicable for autonomic function during the day. Second, this is a cross-sectional study design so we cannot make any conclusion about a cause-effect relationship. Third, it has to be emphasised that most of the correlations found in our population are only weak $(\mathrm{r}<0.3)$. The relationship between OSA, obesity and sympathetic activity is a complicated one that is influenced by several factors, and these confounding factors can influence the correlations. Finally, the majority of our population consisted of subjects without OSA or with only mild OSA. However, this is a direct result of our methodology, as we included all obese subjects and not only those suspected of SDB, implying a representative sample of a paediatric obesity clinic.

In conclusion, OSA is associated with an altered autonomic function, as shown by an increased sympathetic activity on HRV analysis. Measures of hypoxia, in particular, are related to an increased sympathetic tone, suggesting that intermittent hypoxia could be involved in autonomic dysfunction. However, measures of adiposity and age remain important confounding factors in studying the relationship between OSA and autonomic function.

\section{References}

1 Marcus CL. Sleep-disordered breathing in children. Am J Respir Crit Care Med 2001; 164: 16-30.

2 Verhulst SL, Van Gaal L, De Backer W, et al. The prevalence, anatomical correlates and treatment of sleep-disordered breathing in obese children and adolescents. Sleep Med Rev 2008; 12: 339-346.

3 Arens R, Muzumdar H. Childhood obesity and obstructive sleep apnea syndrome. J Appl Physiol 2010; 108: 436-444.

4 Vlahandonis A, Walter LM, Horne RS. Does treatment of SDB in children improve cardiovascular outcome? Sleep Med Rev 2013; 17: 75-85.

5 Verhulst SL, Rooman R, Van Gaal L, et al. Is sleep-disordered breathing an additional risk factor for the metabolic syndrome in obese children and adolescents? Int J Obes 2009; 33: 8-13.

6 Beebe DW. Neurobehavioral morbidity associated with disordered breathing during sleep in children: a comprehensive review. Sleep 2006; 29: 1115-1134.

7 Van Eyck A, Van Hoorenbeeck K, De Winter BY, et al. Sleep-disordered breathing and C-reactive protein in obese children and adolescents. Sleep Breath 2014; 18: 335-340.

8 Van Eyck A, Van Hoorenbeeck K, De Winter BY, et al. Sleep-disordered breathing, systemic adipokine secretion and metabolic dysregulation in overweight and obese children and adolescents. Sleep Med 2015; in press [https://doi.org/10.1016/j.sleep.2015.11.014].

9 Gozal D, Serpero LD, Sans Capdevila O, et al. Systemic inflammation in non-obese children with obstructive sleep apnea. Sleep Med 2008; 9: 254-259.

10 Tauman R, Serpero LD, Sans Capdevila O, et al. Adipokines in children with sleep disordered breathing. Sleep 2007; 30: 443-449.

11 Tsaoussoglou M, Bixler EO, Calhoun S, et al. Sleep-disordered breathing in obese children is associated with prevalent excessive daytime sleepiness, inflammation, and metabolic abnormalities. J Clin Endocrinol Metab 2010; 95: $143-150$.

12 O'Brien LM, Gozal D. Autonomic dysfunction in children with sleep-disordered breathing. Sleep 2005; 28: $747-752$.

13 Bonsignore MR, Parati G, Insalaco G, et al. Continuous positive airway pressure treatment improves baroreflex control of heart rate during sleep in severe obstructive sleep apnea syndrome. Am J Respir Crit Care Med 2002; 166: $279-286$.

14 Task Force of The European Society of Cardiology and The North American Society of Pacing and Electrophysiology. Heart rate variability. Standards of measurement, physiological interpretation, and clinical use. Eur Heart J 1996; 17: 354-381.

15 Liao D, Li X, Rodriguez-Colon SM, et al. Sleep-disordered breathing and cardiac autonomic modulation in children. Sleep Med 2010; 11: 484-488.

16 Aljadeff G, Gozal D, Schechtman VL, et al. Heart rate variability in children with obstructive sleep apnea. Sleep 1997; 20: 151-157.

17 Vitelli O, Del Pozzo M, Baccari G, et al. Autonomic imbalance during apneic episodes in pediatric obstructive sleep apnea. Clin Neurophysiol 2016; 127: 551-555.

18 Spath-Schwalbe E, Gofferje M, Kern W, et al. Sleep disruption alters nocturnal ACTH and cortisol secretory patterns. Biol Psychiatry 1991; 29: 575-584.

19 Tomfohr LM, Edwards KM, Dimsdale JE. Is obstructive sleep apnea associated with cortisol levels? A systematic review of the research evidence. Sleep Med Rev 2012; 16: 243-249.

20 Wabitsch M, Braun U, Heinze E, et al. Body composition in 5-8-y-old obese children and adolescents before and after weight reduction as assessed by deuterium dilution and bioelectrical impedance analysis. Am J Clin Nutr 1996; 64: 1-6.

21 Hauspie R, Roelants M. Growth Charts: Flanders 2004. Vrije Universiteit Brussel. www.vub.ac.be/groeicurven/ english.html Date last accessed: November 7, 2016.

22 Cole TJ, Bellizzi MC, Flegal KM, et al. Establishing a standard definition for child overweight and obesity worldwide: international survey. BMJ 2000; 320: 1240-1243.

23 Iber C. The AASM Manual for the Scoring of Sleep and Associated Events: Rules, Terminology, and Technical Specifications. Westchester, American Academy of Sleep Medicine, 2007. 
24 Verhulst SL, Schrauwen N, Haentjens D, et al. Reference values for sleep-related respiratory variables in asymptomatic European children and adolescents. Pediatr Pulmonol 2007; 42: 159-167.

25 Tarvainen MP, Niskanen JP, Lipponen JA, et al. Kubios HRV - heart rate variability analysis software. Comput Methods Programs Biomed 2014; 113: 210-220.

26 Kaditis AG, Chaidas K, Alexopoulos EI, et al. Effects of adenotonsillectomy on R-R interval and brain natriuretic peptide levels in children with sleep apnea: a preliminary report. Sleep Med 2011; 12: 646-651.

27 Muzumdar HV, Sin S, Nikova M, et al. Changes in heart rate variability after adenotonsillectomy in children with obstructive sleep apnea. Chest 2011; 139: 1050-1059.

28 Baharav A, Kotagal S, Rubin BK, et al. Autonomic cardiovascular control in children with obstructive sleep apnea. Clin Auton Res 1999; 9: 345-351.

29 Martini G, Riva P, Rabbia F, et al. Heart rate variability in childhood obesity. Clin Auton Res 2001; 11: 87-91.

30 Gutin B, Barbeau P, Litaker MS, et al. Heart rate variability in obese children: relations to total body and viscera adiposity, and changes with physical training and detraining. Obes Res 2000; 8: 12-19.

31 Baum P, Petroff D, Classen J, et al. Dysfunction of autonomic nervous system in childhood obesity: a cross-sectional study. PLoS One 2013; 8: e54546.

32 Narkiewicz K, van den Borne PJH, Cooley RL, et al. Sympathetic activity in obese subjects with and without obstructive sleep apnea. Circulation 1998; 98: 772-776.

33 Malakasioti G, Alexopoulos EI, Varlami V, et al. Low morning serum cortisol levels in children with tonsillar hypertrophy and moderate-to-severe OSA. Sleep 2013; 36: 1349-1354.

34 Patacchioli FR, Tabarrini A, Ghiciuc CM, et al. Salivary biomarkers of obstructive sleep apnea syndrome in children. Pediatr Pulmonol 2014; 49: 1145-1152.

35 Goto M, Nagashima M, Baba R, et al. Analysis of heart rate variability demonstrates effects of development on vagal modulation of heart rate in healthy children. J Pediatr 1997; 130: 725-729.

36 Finley JP, Nugent ST. Heart rate variability in infants, children and young adults. J Auton Nerv Syst 1995; 51: 103-108.

37 Lambert E, Straznicky NE, Dawood T, et al. Change in sympathetic nerve firing pattern associated with dietary weight loss in the metabolic syndrome. Front Physiol 2011; 2: 52.

38 Straznicky NE, Eikelis N, Nestel PJ, et al. Baseline sympathetic nervous system activity predicts dietary weight loss in obese metabolic syndrome subjects. J Clin Endocrinol Metab 2012; 97: 605-613. 